\title{
OBESITY, OSTEARTHRITIS AND CLINICAL TREATMENT
}

\author{
andres de la Espriella Rosales ${ }^{1}$, Nadia Lucila Rocha Brito ${ }^{1}$, Renato Frucchi ${ }^{1}$, Gustavo Constantino de Campos ${ }^{1}$, \\ alexandre Felicio Pallo ${ }^{1}$, Márcia Uchôa de Rezende ${ }^{1}$
}

\begin{abstract}
Objective: To evaluate the relationship between BMI and pain and function in patients with OA undergoing medical treatment following OARSI recommendations. Methods: Thirty-eight patients were classified according to their arthritis degree by X-ray and body mass index (BMI). All patients completed the WOMAC, Lequesne, and visual analogue pain scale (VAS) questionnaires at baseline and after six months treatment. All patients were treated with diacerhein and analgesics (according to pain), orthotics (when indicated), and an
\end{abstract}

educational program on osteoarthritis. They were instructed on balanced diet and exercise at least three times a week. Results: There was no significant BMI variation in this study. The higher the initial BMI, the lower the improvement in pain $(p=0.03)$. Pain did not improve significantly $(p=0.2)$. Function improved $(p<0.001)$ in inverse ratio to the initial $\mathrm{BMI}$. Conclusion: BMI determines how patients will improve pain and function.

Keywords: Osteoarthritis. Knee. Obesity. Body mass index.

Citation: Rosales AE, Brito NLR, Frucchi R, Campos GC, Pailo AF, Rezende MU. Obesity, ostearthritis and clinical treatment. Acta Ortop Bras. [online]. 2014;22(3):136-9. Available from URL: http://www.scielo.br/aob.

\section{INTRODUÇÃO}

Osteoarthritis (OA), also called arthritis or osteoarthrosis, has a major impact on mobility and loss of productivity of patients. Patients may present limitations early in life due to OA. ${ }^{1-3}$ Gonarthritis is among the most debilitating osteoarthroses, greatly decreasing patients' quality of life. ${ }^{4}$

The high body mass index, as well maintaining this condition for a long period of time, are risk factors for OA.,6 Weight loss alone, in addition to benefits in other pathologies, has an effect on OA decreasing pain, improving quality of life and functional scores. ${ }^{7}$ In Brazil, according to data from IBGE, in recent decades there has been a significant increase in overweight in men and women, i.e., body mass index (BMI) between 25.1 and 30 and obesity (BMI between 30.1 and 35), which poses a great number of people at risk to develop OA and limitations it imposes. ${ }^{8}$ OARSI (Osteoarthritis Research International) seeks to publish guidelines on the various forms of treatment of osteoarthritis of the knee, among them education, phone calls and non-drug methods such as physical therapy, exercise, acupuncture, mind-body therapies and use of orthoses (insoles, canes, crutches and knee pads). Finally, OARSI also defines guidelines on pain medications and osteoarthritis modifying disease..$^{9,10}$ This study aims to evaluate the relationship between BMI and pain and function in the short term, in patients undergoing clinical treatment for OA following the recommendations of OARSI.

\section{METHODS}

This is a pilot study to assess the relationship between BMI and pain complaints and functionality of patients with osteoarthritis. Thirty-eight patients with gonarthritis, with or without arthritis in other joints were included. All patients were asked about co-morbidities and previous sports activity. Were also X-rayed the affected joints and classified them according to the classification of Kellgren and Lawrence (KL). ${ }^{11}$

For anthropometric assessment, body mass index (BMI) was used for its easy applicability and low operating cost, and defined as the weight in kilograms divided by the squared height in meters. The scale used to measure the weight and height was an electrical balance brand Filizola ${ }^{\circledR}$.

The included patients were already receiving diacerhein and painkillers for over than three months before inclusion in the study. Orthoses were prescribed as needed (valgizing insoles, varizing insoles, or canes).

After inclusion, patients participated in two days of classes with seven teams (orthopedists, psychologists, physiotherapists, occupational therapists, physical trainers, nutritionists and social workers) with two months interval. In these classes, it was explained what was osteoarthritis and its treatment.

In the program, there were practical physiotherapy classes where patients did stretching and strength exercises, learning to perform them without pain. All patients were encouraged to

\section{All the authors declare that there is no potential conflict of interest referring to this article.}

1. Institute of Orthopedics and Traumatology, Hospital das Clínicas da Faculdade de Medicina da Universidade de São Paulo, São Paulo, SP, Brazil.

Work developed at LIM 41 - Laboratory of Medical Research of the Musculoskeletal System and Osteometabolic and Degenerative diseases, Department of Orthopedics and Traumatology, Faculdade de Medicina da Universidade de São Paulo, São Paulo, SP, Brazil.

Correspondence: Márcia Uchôa de Rezende, Rua Cristiano Viana, 670 apto. 53, Cerqueira Cesar, 05411-001 São Paulo, SP, Brazil. murezende@uol.com.br 
perform these exercises at home for at least three times a week. Patients received an apostille (PARQVE ${ }^{\circledR}$ apostille from IOTHC-USP) and a DVD reinforcing lectures' guidelines on the pathology and its treatment containing all images of exercises performed in practical classes.

A nutritionist reinforced in two lessons in the importance of eating every three hours, drinking at least eight glasses of water per day, adding whole grains in the diet, removing fried foods, soft drinks and high concentration of salt in the diet.

All patients completed the WOMAC questionnaires (Western Ontario and McMaster Universities Osteoarthritis Index) and Lequesne questionnaire on the joint function and arthropathy. These questionnaires were completed at admission in the study and four months after the second class. Pain was assessed by the visual analog scale (VAS) and by WOMAC fraction for pain assessment (WOMAC pain).

\section{STATISTICAL ANALYSIS}

Descriptive statistics of quantitative variables was performed by calculating mean; standard deviation; standard mean error; median; and maximum and minimum values. Comparison of the same variable in two distinct time periods was performed using the Wilcoxon test. BMI values were correlated to changes in pain and function using the Spearman test. Ordinal values were correlated to variations using the Kruskal-Wallis test. If significant difference between the groups was achieved, discrimination was taken by Dunn's post-test. In all cases we used a significance level of $5 \%$ (alpha $=0.05)$.

\section{RESULTS}

The study group was formed by four men and 34 women aged 47-83 years old (mean 63.2 years). Twenty-nine patients had only knee injuries. The remaining (nine) had at least one other affected joint (hand, elbow, spine, feet, hips). Only ten patients did not have any other comorbidity (diabetes, hypertension, dyslipidemia, thyroid disorder, sleep apnea, Crohn's disease). The vast majority (26 patients) practiced no physical activity. We observed eight patients with grade I (K\&L), eleven with grade II, thirteen with grade III and six with grade IV. The results regarding change in VAS, WOMAC-pain, WOMAC and Lequesne did not correlate to the initial degree of osteoarthritis. However, the group that decreased BMI tended to improvement in pain and function and the group that increased BMI tended to improve pain and function (Kruskal-Wallis test, not significant). The higher initial BMI determined lower improvement of pain (Spearman test, $p=0.03$ ).

The assessment of pain by visual analog scale (VAS) showed improvement but not significant. In some patients pain greatly improved and in others it worsens. The analysis of the entire group showed no clinically or statistically significant improvement ( $p=0.3668$ ). (Table 1)

Similar to the assessment of pain by VAS, analysis of pain by the WOMAC pain instrument (Table 2) also showed no significant improvement $(p=0.2403)$.

Significant improvements were in WOMAC (Table 3) and Lequesne (Table 4), both with $p<0.001$.

Despite efforts to educate the staff about the importance of healthy eating, this group adhered scarcely to the guidelines. There were patients who lost 4.9 BMl points and others who Acta Ortop Bras. 2014;22(3):136-9 increased by up to 2 points. (Table 5) Thus, the group average group did not vary significantly $(p=1)$, but showed a correlation between baseline BMI and the degree of improvement in the WOMAC function. The higher the BMI, the lower was the expected functional improvement.

Table 1. Results of VAS (visual analog scale for pain) from patients at the beginning of treatment (VAS pre), and six months after (four months after classes) (VAS post). Difference between VAS values (DVAS). Comparison between data pre-and post- treatment.

\begin{tabular}{c|c|c|c}
\hline & VAS pre & VAS post & DVAS \\
\hline Mean & 60,2 & 57,6 & $-2,5$ \\
\hline Standard deviation & 3,3 & 3,5 & 4,2 \\
\hline Median & 59,5 & 60 & 0 \\
\hline Standard deviation & 20,6 & 21,6 & 26,2 \\
\hline Minimum & 16 & 25 & -51 \\
\hline Maximum & 100 & 100 & 55 \\
\hline Number & 38 & 38 & 38 \\
\hline
\end{tabular}

Wilcoxon Test $\mathrm{p}=0.3668$

Table 2. Results of WOMAC pain from patients at the beginning of treatment (WD pre), and six months after (four months after classes) (WD post). Difference between WOMAC pain values (DWD). Comparison between data pre-and post- treatment.

\begin{tabular}{c|c|c|c}
\hline & WD pre & WD post & DWD \\
\hline Mean & 8,7 & 8,2 & $-0,4$ \\
\hline Standard deviation & 0,6 & 0,6 & 0,6 \\
\hline Median & 9 & 8 & $-0,5$ \\
\hline Standard deviation & 3,4 & 4 & 4 \\
\hline Minimum & 2 & 0 & -9 \\
\hline Maximum & 16 & 17 & 7 \\
\hline Number & 38 & 38 & 38 \\
\hline
\end{tabular}

Wilcoxon test $p=0.2403$ 
Table 3. Results of WOMAC from patients at the beginning of treatment (W pre), and six months after (four months after classes) (W post). Difference between WOMAC values (DW). Comparison between data pre- and post- treatment.

\begin{tabular}{c|c|c|c}
\hline & W pre & W post & DW \\
\hline Mean & 46,7 & 43,2 & $-3,5$ \\
\hline Standard deviation & 3,08 & 2,87 & 3 \\
\hline Median & 49,5 & 39,5 & 0,5 \\
\hline Standard deviation & 19 & 17,7 & 18,8 \\
\hline Minimum & 12 & 14 & -51 \\
\hline Maximum & 89 & 83 & 33 \\
\hline Number & 38 & 38 & 38 \\
\hline
\end{tabular}

Wilcoxon test $\mathrm{P}<0.0001$

Table 4. Results of LEQUESNE from patients at the beginning of treatment (LQ pre), and six months after (four months after classes) (LQ post). Difference between LEQUESNE values (DLQ). Comparison between data pre- and post- treatment.

\begin{tabular}{c|c|c|c}
\hline & LQ pre & LQ post & DLQ \\
\hline Mean & 57,6 & 13,3 & $-1,3$ \\
\hline Standard deviation & 3,5 & 1,78 & 2 \\
\hline Median & 60 & 12 & 0,5 \\
\hline Standard deviation & 21,6 & 11 & 12,1 \\
\hline Minimum & 25 & 4,5 & $-7,5$ \\
\hline Maximum & 100 & 75 & 8 \\
\hline Number & 38 & 38 & 38 \\
\hline
\end{tabular}

Wilcoxon test $\mathrm{P}<0.0001^{*} \mathrm{~S}$

\section{DISCUSSION}

Our study confirms results from literature on the relationship between feminine gender and obesity with osteoarthritis. ${ }^{12}$ The number of women in the program is much greater than the men's. The age range of participants was wide, but it consisted only of patients in the fifth decade onwards. There were no young patients with post-traumatic arthritis, and patients were mostly obese or overweight.
Table 5. Results of Body Mass Index (BMI) of patients at the beginning of treatment (BMl pre), and 6 months after (four months after class) (BMl post). Difference between values of BMI (DBMI). Comparison of data pre e post. Correlation between BMI-pre, BMI-post, and DBMI and variations of pain (DVAS, DWD) e variations of function (WOMAC and LEQUESNE).

\begin{tabular}{c|c|c|c|c|c|c|c}
\hline & BMI pre & BMI post & DIMC & DVAS & DWD & DW & DLQ \\
\hline Mean & 30,8 & 30,6 & $-0,2$ & $-2,5$ & $-0,4$ & $-3,5$ & $-1,3$ \\
\hline $\begin{array}{c}\text { Standard } \\
\text { deviation }\end{array}$ & 0,8 & 0,8 & 0,22 & 4,2 & 0,6 & 3 & 2 \\
\hline Median & 29,9 & 29,7 & $-0,2$ & 0 & $-0,5$ & 0,5 & 0,5 \\
\hline $\begin{array}{c}\text { Standard } \\
\text { deviation }\end{array}$ & 5,1 & 5,3 & 1,4 & 26,2 & 4 & 18,8 & 12,1 \\
\hline Minimum & 20,1 & 20,7 & $-4,9$ & -51 & -9 & -51 & $-7,5$ \\
\hline Maximum & 42,2 & 41,8 & 2,7 & 55 & 7 & 33 & 8 \\
\hline Number & 38 & 38 & 38 & 38 & 38 & 38 & 38 \\
\hline
\end{tabular}

Wilcoxon test $\mathrm{p}=1$ (IMC pre $\mathrm{x}$ IMC post). Spearman test:

BMl pre $x$ DVAS $p=0,5$; BMl pre $x$ DWD $p=0,3$; BMl pre $x$ DW $p=0,03^{*}(R=-0,35)$; BMl pre $x D L p=0,96$; BMl post $x$ DVAS $p=0,67$; BMl post $x$ DWD $p=0,48$; BMl post $x$ DW $p=0,09$; BMl post $x$ DLQ $p=0,8$; DIMC $x$ DVAS $p=0,87 ;$ DIMC $x$ DWD $p=0,45 ;$ DIMC $x$ DW p =0,06; DIMC $\times$ DLQ $p=0,97$

Physical incapacity, as a result of pain and loss of joint function, reduced quality of life. ${ }^{13-15}$ Regardless of the degree of arthritis, we found that the group which lowered their BMI showed improvement of pain and function and the group that increased their BMI worsened both pain and function. The group with higher BMI showed less improvement of pain. These results showed no statistical significance, perhaps due to the small sample size, or perhaps due to lack of control of the number of hours of exercise per week, another important factor for symptom relief. $\mathrm{BMI}$ is considered by many authors as the best indicator of body mass in an adult. However, it has two important limitations. The first limitation is the proportionality of the body, for people with short legs show increased BMI. The second is regarding fat-free mass, especially in men, as muscular individuals and athletes may have a BMI in the obese range. ${ }^{16}$ Nevertheless, several studies have shown that BMI correlates well with the amount of body fat determined by direct measures such as densitometry, bioelectrical impedance analysis (BIA), skinfold thickness, waist/hip ratio (WHR) and waist circumference (WC). ${ }^{17}$

We observed a direct relationship between weight loss and improved function by both Lequesne questionnaire, as by WO$M A C$ rating $(p<0.0001)$. This finding reinforces the importance of weight loss as a mainstay in osteoarthritis treatment. There was no relationship between improved function with pain improvement. This finding may be the result of an ineffective method of pain assessment or due to chronic disease, altering the perception of pain. 
Despite the efforts of the entire team to make patients adhere to the nutritionist guidance of a scheduled and low glycemic diet intended to weight loss, this population adhered very little, as reported in other related studies. ${ }^{18}$

\section{CONCLUSION}

Despite the difficulty of compliance, guidance to diet intended to weight loss, practice of physical activity and physiotherapy should be encouraged as they have benefits not only for the improvement of pain and function in osteoarthritis but also for other chronic diseases such as diabetes and hypertension (common diseases in this population).

\section{ACKNOWLEDGEMENTS}

We thank Dr. Raul Bolliger Neto for his assistance in conducting statistical analysis.

\section{REFERENCES}

1. Dominick KL, Ahern FM, Gold CH, Heller DA. Health-related quality of life among older adults with arthritis. Health Qual Life Outcomes. 2004;2:5.

2. Mathers CD, Stein C, Fat, DM, Rao C, Inoue M, Tomijima N, et al. Global Burden of disease 200: Version 2 methods and results. Global programme on Evidence for Health Policy Discussion. Geneva: World Health Organization; 2002.

3. Parmet S, Lynn C, Glass RM. JAMA patient page. Osteoarthritis of the knee. JAMA. 2003;289(8):1068.

4. Kwok WY, Vliet Vlieland TPM, Rosendaal FR, Huizinga TW, Kloppenburg M. Lomitations in daily activities are the major determinant of reduced health-related quality of life in patients with hand osteoarthritis. Ann Rheum Dis. 2011;70(2):334-6.

5. Felson DT, Anderson JJ, Naimark A, Walker AM, Meenan RF. Obesity and knee osteoarthritis. The Framingham Study. Ann Intern Med. 1988;109(1):18-24.

6. Wills AK, Black S, Cooper R, Coppack RJ, Hardy R, Martin KR, et al. Life course body mass index and risk of knee osteoarthritis at the age of 53 years: evidence from the 1946 British birth cohort study. Ann Rheum Dis. 2012;71(5):655-60.

7. Bliddal H, Leeds AR, Stigsgaard L, Astrup A, Christensen R. Ann Rheum Dis. 2011; 70(10):1798-803.

8. IBGE. POF 2008-2009: desnutrição cai e peso das crianças brasileiras ultrapassa padrão internacional, 2010. Disponível em: http://www.ibge.gov. br/home/presidencia/noticias/noticia_visualiza.php?id_noticia=1699\&id_ pagina $=1 /$

9. Zhang W, Moskowitz RW, Nuki G, Abramson S, Altman RD, Arden N, et al OARSI recommendations for the management of hip and knee osteoarthritis, part II: OARSI evidence-based, expert consensus guidelines. Osteoarthritis Cartilage. 2008;16(2):137-62.

10. Zhang W, Nuki G, Moskowitz RW, Abramson S, Altman RD, Arden NK, et al. OARSI recommendations for the management of hip and knee osteoarthritis, part III: changes in evidence following systematic cumulative update of research published through January 2009. Osteoarthritis Cartilage. 2010;18(4):476-99.

11. Kellgren JH, Lawrence JS. Radiological assessment of osteo-arthrosis Ann Rheum Dis. 1957;16(4):494-502.

12. Leach RE, Baumgard S, Broom J. Obesity: its relationship to osteoarthritis of the knee. Clin Orthop Relat Res. 1973;(93):271-3.

13. Hurley MV. Muscle, exercise and arthritis. Ann Rheum Dis. 2002;61(8);673-5

14. O'Reilly SC, Jones A, Muir KR, Doherty M. Quadriceps weakness in knee osteoarthritis: the effect on pain and disability. Ann Rheum Dis.1998;57(10):58894.

15. Fransen M, McConnell S, Bell M. Therapeutic exercise for people with osteoarthritis of the hip or knee. A systematic review. J Rheumatol. 2002;29(8):1737-45.

16. Anjos LA. [Body mass index (body mass.body height-2) as indicator of nutritional status in adults: review of the literature]. Rev Saude Publica. 1992;26(6):431-6.

17. Cervi A, Franceschini SC, Priore SE. Análise crítica do uso do índice de massa corporal para idosos. Rev Nutr. 2005;18(6):765-75.

18. Campbell R, Evans M, Tucker M, Quilty B, Dieppe P, Donovan JL. Why don't patients do their exercises? Understanding non-compliance with physiotherapy in patients with osteoarthritis of the knee. J Epidemiol Community Health. 2001;55(2):132-8. 